\title{
BMJ Open Learning from the transfer of a fellowship programme to support primary care workforce needs in the UK: a qualitative study
}

Carol Bryce, Rachel Russell, Jeremy Dale

To cite: Bryce C, Russell R, Dale J. Learning from the transfer of a fellowship programme to support primary care workforce needs in the UK: a qualitative study. BMJ Open 2019;9:e023384. doi:10.1136/ bmjopen-2018-023384

- Prepublication history for this paper is available online. To view these files, please visit the journal online (http://dx.doi. org/10.1136/bmjopen-2018023384).

Received 5 April 2018 Revised 22 November 2018 Accepted 26 November 2018

D Check for updates

(c) Author(s) (or their employer(s)) 2019. Re-use permitted under CC BY-NC. No commercial re-use. See rights and permissions. Published by BMJ.

Unit of Academic Primary Care, University of Warwick, Warwick Medical School, Coventry, UK

Correspondence to

Professor Jeremy Dale;

jeremy.dale@warwick.ac.uk

\section{ABSTRACT}

Objectives Service redesign, including workforce development, is being championed by UK health service policy. It is allowing new opportunities to enhance the roles of staff and encourage multiprofessional portfolio working. New models of working are emerging, but there has been little research into how innovative programmes are transferred to and taken up by different areas. This study investigates the transferability of a 1-year postCertification of Completion of Training fellowship in urgent and acute care from a pilot in the West Midlands region of England to London and the South East.

Design A qualitative study using semistructured interviews supplemented by observational data of fellows' clinical and academic activities. Data were analysed using a thematic framework approach.

Setting and participants Two cohorts of fellows (15 in total) along with key stakeholders, mentors, tutors and host organisations in London and the South East (LaSE). Fellows had placements in primary and secondary care settings (general practice, emergency department, ambulatory care, urgent care and rapid response teams), together with academic training.

Results Seventy-six interviews were completed with 50 participants, with observations in eight clinical placements and two academic sessions. The overall structure of the West Midlands programme was retained and the core learning outcomes adopted in LaSE. Three fundamental adaptations were evident: broadening the programme to include multiprofessional fellows, changes to the funding model and the impact that had on clinical placements. These were felt to be key to its adoption and longer-term sustainability.

Conclusion The evaluation demonstrates a model of training that is adaptable and transferable between National Health Service regions, taking account of changing national and regional circumstances, and has the potential to be rolled out widely.

\section{INTRODUCTION}

UK health service policy is looking to service redesign as a way of addressing the challenges facing the National Health Service (NHS). ${ }^{1-3}$ Within primary care, training initiatives (including additional training in hard to
Strengths and limitations of this study

- Few studies have evaluated the delivery of new training programmes for general practitioners and primary care professionals in terms of their transferability from one area to another.

- This study evaluated an innovative additional year of training and had a high level of participation from the cohort eligible for inclusion, with their perspectives gathered at a number of stages of the programme.

- By including a wide range of individuals who worked with the fellows including stakeholders, host organisation leads and colleagues, the study gained a broad perspective of the adoption of the fellowship programme and factors that influenced its transferability.

- Although limited to two regions, together these cover $31.8 \%$ of the population of the country and two of the four Local Education Training Boards in England, so strengthening the generalisability of the findings.

recruit posts, the development of portfolio roles for both newly qualified staff and those reaching the end of their careers and workforce development in teams wider than general practitioners (GPs)) are suggested as ways of enhancing the roles of staff, including nurses. ${ }^{34}$ This has included funding for 250 post-Certification of Completion of Training (CCT) training posts in England, targeted at areas with the poorest GP recruitment, to enable GPs to access additional training in a specialism of interest while addressing local need. ${ }^{4}$ Such initiatives are important at a time when the number of GPs intending to reduce their hours or leave general practice is rising in the face of increasing workload. ${ }^{56}$ They offer experience (cross-sector working, skills enhancement including leadership and management training, and clinical skills training) that goes further than that included in the current 3-year vocational training schemes. ${ }^{78}$ This mirrors the expanding remit of general practice, with recognition that 
Box 1 Aims and structure of fellowship programme in West Midlands

Seven general practitioners (GPs) within 3 years of post-Certification of Completion of Training participated in the programme in the West Midlands

\section{Aims}

- To enhance the skills and experience of GPs in urgent/emergency care teams

- To enable GPs to apply enhanced urgent and acute skills to support the development of alternative community-based care pathways

- To raise GP interest in hybrid emergency/urgent and primary care roles

- To support the national policy drive for integration of primary, secondary and social care

\section{Programme structure}

- $40 \%$ time in primary care: GP training practice

- $40 \%$ time in clinical attachments: three attachments each of 4 months' duration comprising emergency department, a medical admissions unit and an ambulance service

- $20 \%$ academic study: undertaking a bespoke postgraduate certificate in urgent and acute care and participation in an action learning set

\section{Core learning outcomes}

- Demonstrate the ability to diagnose and assess urgent presentations in long-term illnesses

- Formulate, implement and evaluate current pathways of care according to best evidence

- Show understanding of frailty and complex co-morbidities, particularly in the elderly and how such patients are appropriately managed

- Demonstrate competence in the interpretation and evaluation of evidence and the application of appropriate treatment and assessment

- Apply knowledge and skills to the management of urgent care

- Critically interpret and evaluate the current evidence behind urgent care

traditional models of training and continuing professional development in general practice are no longer sufficient to prepare individuals for roles that cross boundaries of care. ${ }^{910}$

Uptake of service innovation within the NHS is known to be slow with few formal mechanisms existing for spreading learning across services or different geographical areas. ${ }^{11}$ Within primary care, evidence suggests the fit between the innovation and the local context is crucial if implementation is to be successful. ${ }^{12}$ Where innovation has been shown to be successful, there has consistently been strong leadership or champion buy in and appropriate funding alongside perceived external and internal need. ${ }^{12-16}$ Much of the evidence that does exist focuses on facilitators and barriers to innovation with less evidence of how and why some are successful. ${ }^{12}$

We recently reported an evaluation of a 1-year post-CCT fellowship programme, developed and piloted by Health Education England (HEE), West Midlands, that provided recently trained GPs with advanced skills training in urgent and acute care, leadership and academic practice. ${ }^{17}$ Details of the fellowship programme are shown in box 1 . Although positively evaluated, questions remained over scalability and transferability to more complex health service settings. ${ }^{17}$

In 2016, HEE, London and the South East (LaSE) adopted the West Midlands fellowship programme throughout the region, so creating an opportunity to study its transferability to multiple contrasting areas. Whereas the secondary care-based elements of the West Midlands' pilot were located in relatively small county hospitals, the LaSE scheme included large inner city hospitals in socially diverse settings. Hence, the aims of this evaluation were to consider the transferability and implementation of the fellowship scheme, in particular looking at how and why it evolved, in order to draw out implications for the further roll-out of such workforce initiatives.

\section{METHODS}

This qualitative study comprised interviews with key individuals, along with observations of fellows in a cross section of workplace settings, to gain in-depth understanding of views and experiences relating to the transfer of a workforce programme from one setting to another.

\section{Recruitment and data collection}

All fellows in each of two cohorts of the 1-year urgent/ emergency care fellowship programme implemented in LaSE in 2016 were invited to take part in the study, along with their mentors and key individuals they identified in each of their clinical placements. In addition, we invited key stakeholders responsible for the implementation of the programme, including HEE primary care leads, quality and performance managers and academic leads.

All eligible individuals received written study information and were verbally consented. They were also informed what the data would be used for and that confidentiality would be assured. All data were anonymised with unique identifiers assigned to each participant according to the group to which they belonged (HEE=stakeholders and Health Education England staff members, M=fellow's mentor, $\mathrm{F}=$ fellow and $\mathrm{H}=$ keyindividual in the healthcare provider organisation).

Semistructured interviews were conducted face-to-face or over the telephone and lasted between 20 and $45 \mathrm{~min}$. Initial interviews, conducted around 6 months into the fellowship, explored interviewee's aims, expectations and experiences of the fellowship programme. Second interviews were conducted on or after completion of the programme and focused on the overall experience of the fellowship and its impact on career plans (fellows) and organisational impacts, including capacity building (stakeholders and hosts).

Observations of fellows (10 in total) were pragmatically chosen to cover all primary and secondary care settings in which the fellows were hosted, as well as academic days, and to minimise disruption to clinical teams. An observation checklist was used to record evidence of teamwork, 
integrated care working, communication across settings, teaching and academic activity. Observations lasted between 4 and 7 hours during which time members of the clinical team with whom they were located were opportunistically asked to participate in short interviews.

\section{Data analysis}

All interviews were recorded, transcribed verbatim, anonymised and checked for accuracy by CB and RR. Analysis was aided by the use of Nvivo V.11 software package. Using a thematic framework approach to interrogate the data and identify key themes, ${ }^{18}$ initial codes were deductively drawn from the research questions. Through further reading of the transcripts, we inductively coded for any elements not previously captured. A thematic framework was devised using an iterative process until all the codes had been identified. ${ }^{18} \mathrm{CB}$ and JD met regularly to discuss the analysis and identification of emergent themes. Illustrative quotes were identified to elucidate each theme.

\section{Patient and public involvement}

Patients and public were not directly involved in this study.

\section{RESULTS}

\section{Participants and settings}

Of 17 eligible fellows, 15 agreed to participate in the evaluation; one had personal circumstances that prevented them from doing so. In addition, 35 stakeholders, provider organisation clinical leads, GP tutors and mentors participated in planned interviews. Twenty participants were involved in a second interview and six were interviewed a total of three times, as shown in table 1, giving a total of 76 interviews. The timing of when data collection occurred, in relation to the employment period of each of the fellows, determined the extent to which they could each be followed up.

An additional 27 interviews (lasting between 5 and $15 \mathrm{~min}$ ) were completed opportunistically during observation sessions. These included members of GP, emergency department, ambulatory care, urgent care and rapid response teams.

Table 2 shows the mix of clinical placements that were experienced by the 15 participating fellows. While most had 2 days/week in general practice, the secondary

\begin{tabular}{lccc}
\hline Table 1 & Interview data collection & & \\
\hline Role & $\begin{array}{l}\text { Initial } \\
\text { interviews }\end{array}$ & $\begin{array}{l}\text { Supplementary } \\
\text { interviews }\end{array}$ & Total \\
\hline $\begin{array}{l}\text { Health Education England } \\
\text { staff and stakeholders } \\
\text { (including course tutor) }\end{array}$ & 10 & 5 & 15 \\
$\begin{array}{l}\text { Host provider organisations } \\
\text { Fellows }\end{array}$ & 9 & 3 & 12 \\
\hline Mentors/tutors & 15 & 18 & 33 \\
\hline Total & 16 & & 16 \\
\hline
\end{tabular}

care placements were highly variable and for one fellow included no direct patient contact.

\section{Comparison with and learning from the West Midlands pilot}

Interviewees described a high level of commitment between HEE partners in West Midlands and LaSE to share learning relevant to the transfer of the fellowship programme, particularly during the year prior to the LaSE fellowship launch. Respondents also highlighted the key role that programme champions in LaSE (from regional level to local clinical educators) played in its successful implementation.

The overall aims and structure of the West Midlands programme were retained by LaSE (see Box 1). LaSE adopted the same core learning outcomes, adding a further two covering understanding of ambulatory care and working towards admission avoidance strategies. While the West Midlands fellowship programme was administered across one HEE local area, in LaSE it was across four reflecting a more complex and varied administrative landscape. There was evident commitment between HEE partners in West Midlands and LaSE to share learning relevant to the transfer of the fellowship programme. HEE leads had met and discussed how the pilot programme was set up in the West Midlands, and this fed directly into the development of the LaSE programme.

We identified three clear areas of adaptation which will now be explored in more detail.

\section{Acceptability and experience of the scheme}

The stakeholders, mentors and hosts in LaSE viewed the programme favourably, stating that they would be willing to host a fellow in the future.

I can't praise him [academic mentor] highly enough actually, I think his style as a programme lead has been brilliant. So in terms of the academic days they're very good. (F10)

The programme was also felt by most participants to be fulfilling expectations that it was preparing fellows for portfolio careers, including leadership and academic roles

It [fellowship] helps in a number of ways. You can apply it to the academic side, you've got the post-graduate certificate. You can apply it to the fact that you've got a range. (F07)

\section{The development of a multiprofessional fellowship model}

While the West Midlands pilot programme only included GPs, at LaSE it was broadened to include advanced nurse practitioners (ANPs) and physician associates (PAs): two ANPs were included in cohort 1, and two ANPs and one PA in cohort 2. Commissioners and the programme team drove this change as they considered multiprofessional working a progressive development: 
Table 2 Fellows placement experience by profession

\section{Profession GP placement Secondary care placement}

\begin{tabular}{|c|c|c|}
\hline ANP & $\begin{array}{l}\text { Unassigned but included ad hoc work } \\
\text { in extended hours sessions. }\end{array}$ & $\begin{array}{l}1 \text { day/week stroke reduction project. } 12 \text { months. } \\
3 \text { days/week working for local community education provider network on } \\
\text { quality and clinical assurance. } 12 \text { months. }\end{array}$ \\
\hline ANP & None organised. & Urgent care centre. 12 months. \\
\hline ANP & 2 days/week 12 months. & $\begin{array}{l}1 \text { day emergency department. } 12 \text { months. } \\
1 \text { day urgent care. } 12 \text { months. }\end{array}$ \\
\hline ANP & 2 days/week two 6-month placements. & $\begin{array}{l}2 \text { days secondary care including ambulatory care, acute medical unit, } \\
\text { integrated networks. } 12 \text { months. }\end{array}$ \\
\hline GP & $\begin{array}{l}2 \text { days/week (including } 1 \text { day project } \\
\text { work) } 6 \text { months. } \\
2 \text { days/week } 6 \text { months. }\end{array}$ & $\begin{array}{l}2 \text { days ambulatory care including virtual ward outreach nursing team } \\
\text { attachment. } 6 \text { months. } \\
2 \text { days emergency department. } 6 \text { months. }\end{array}$ \\
\hline GP & Variable sessions over 12 months. & $\begin{array}{l}2 \text { days/week urgent care walk-in centre. } 12 \text { months. } \\
2 \text { days/week community independence service-virtual ward. } 12 \text { months. }\end{array}$ \\
\hline
\end{tabular}

\begin{tabular}{|c|c|c|}
\hline GP & $\begin{array}{l}1 \text { day/week. } \\
1 \text { day nursing home (that practice } \\
\text { managed). } 12 \text { months. }\end{array}$ & 2 days/week rapid response intermediate care service. 12 months. \\
\hline GP & $\begin{array}{l}2 \text { days/week (already working in } \\
\text { surgery prior to fellowship). }\end{array}$ & $\begin{array}{l}\text { No clinical placements in secondary care. } \\
\text { (worked at CCG level developing a paediatrics fellowship initiative). } \\
12 \text { months. }\end{array}$ \\
\hline GP & 2 days/week. 12 months. & $\begin{array}{l}1 \text { day/week ambulatory care. } 12 \text { months. } \\
1 \text { day/week geriatrics and frailty-organisational service delivery project. } \\
12 \text { months. }\end{array}$ \\
\hline GP & 2 days/week. 12 months. & 2 days/week urgent care. 12 months. \\
\hline GP & 2 days/week. 12 months. & $\begin{array}{l}1 \text { day/week urgent care. } 12 \text { months. } \\
1 \text { day/week CCG working on service improvement linked to urgent care } \\
\text { placement. } 12 \text { months. }\end{array}$ \\
\hline GP & 2 days/week. 12 months. & $\begin{array}{l}1 \text { day/week emergency department. } 12 \text { months. } \\
1 \text { day/week urgent care. } 12 \text { months. }\end{array}$ \\
\hline
\end{tabular}

ANP, advanced nurse practitioner; CCG, Clinical Commissioning Group; GP, general practitioner.

... the model for urgent and emergency care is predicated in the future on a mixed economy of health professionals. (H04)

Nursing fellows welcomed the broadening of the scheme as they described a lack of professional development or upskilling opportunities.

So, [ANPs] do not have much opportunity to upskill clinically ... there are quite a few programmes geared towards GP trainers. (Fellow 01)

The teaching element of the programme was seen to be enhanced by the multiprofessional mix:
So one advantage of our programme is that we take all comers, not just GPs, and that's been incredibly useful. Certainly I've noticed when teaching the group ... a very heterogeneous group is always better to be teaching and working with. (HEE02)

Although the multiprofessional mix was generally well-received, there were some concerns raised about the suitability of non-GPs and the available clinical placements in acute settings. Some of the ANP and PA fellows had difficulty in accessing suitable placements, and some of the placement mentors were unsure of how to best use the fellow: 
Trying to mix those three cohorts of clinicians who come from significantly different backgrounds was going to be challenging ... so there wasn't a clear syllabus about what they needed to do, there wasn't clear competency documents that we would expect for signing off for F2s or paramedics. (Mentor 24)

This highlights the need for all participants in the scheme to have clear information on the role of the fellows and the programme purpose. While the fellowship programme was not designed to be competency-based, concerns were raised about the experience and qualification levels of the nursing fellows compared with GP fellows.

They're so variable, because you just don't know what background they're coming with. So you know, with the GPs traditional training, they've had twoyears in hospital medicine and a year in general practice. With an ANP, it depends on what the training's been previously. (Mentor 22)

Placement difficulties also arose over uncertainty regarding ANPs' indemnity in some settings:

... it wasn't even the funding, I think it was the cover, insurance or litigation. I wasn't able to work there.

(Fellow 01)

Despite these difficulties, including ANPs and PAs in the fellowship programme was generally viewed positively as a means of providing upskilling opportunities, encouraging individuals to pursue more challenging roles and to increase capacity.

I think if we can get them to autonomous practising at urgent emergency care level then they are a very, very employable asset. (Mentor 23)

\section{Changes to the funding model}

While the initial pilot of the fellowship programme had been fully funded by HEE West Midlands, in LaSE the funding climate did not allow this and alternative funding mechanisms were needed:

In the West Midlands they were paying $100 \%$ of the salary of the individuals involved in the fellowship, and we felt that actually that wasn't a model that would be sustainable as we moved forwards. So we devised a different funding model which was a bursary based model which then left the service element to be funded through service providers and clinical commissioners. (HEE05)

In LaSE, the academic element of the fellowship continued to be funded through HEE, with the remaining costs of the scheme being funded by the primary and secondary care organisations providing clinical placements. While this enabled the inclusion of a larger number of fellows, it also led to increasing variation in employers' expectations of the fellows. In addition, the complex employment arrangements were time consuming to set up and manage:

I've tried to be quite proactive and I've engaged the employers for several months beforehand and tried to make really sure they know what they're offering and whose responsibility is whose. (HEE04)

The LaSE programme required a Clinical Commissioning Group (CCG) or a GP federation/partnership to host the fellow and act as their main employer, taking on responsibility to ensure that the fellowship was financially viable, and cross-charging for the time the fellows spent in other clinical settings:

If you take on somebody full time in a Fellowship position the salary cost is $£ 100,000$ and the Fellowship grant is $£ 30,000$, so you have to balance the $£ 70,000$ ...... So we have to find them projects to do with organisations that are happy for us to cross charge them for their clinical time. (Host 02)

This funding model allowed for flexibility, enabling most fellows to build placements around their interests; however, a few fellows cited the necessity of their host to recoup costs as the main reason they lacked the breadth of experience they had envisioned:

I feel completely cheated. I feel like I've been used as a commodity ... for my year my key aim was to have the clinical side of it, and that hasn't happened and isn't going to. (Fellow 10)

Organisational stakeholders considered that host organisations' investment in the programme was central to its relevance and sustainability:

Because service is not getting a freebee or a total freebee they are actually committed to ensuring and investing in it to get the right thing for them as well as the programme itself. So it is buy in ... it is a model that can then be replicated across the system as it demonstrates that providers recognise that this kind of approach is really important both for developing future leadership service but also demonstrating an integrated approach to service delivery. (HEE05)

\section{Clinical placement experience}

Although the programme in LaSE retained the same 40:40:20 proportions as in the West Midlands scheme (see Box 1), the organisation of clinical placements differed. In the West Midlands' pilot fellows worked in one GP practice and rotated through three service placements, each lasting 4 months. In LaSE, each fellow had to work with their employing organisation to arrange their placements both in GP and urgent care, resulting in a variety of lengths of placement and experience. This change meant that each fellow had more individualised programme as shown in table 2.

It's worked really well for me ... sorting things out myself and not just kind of fitting into a programme that exists. (Fellow 11) 
Making sure that there's a bit of flexibility in it means that, particularly for the candidate, they will get the best experience rather than just having a rigid 'you will do this, you will do that'. (Host 02)

Most fellows viewed this adaptation positively, but some were left without the anticipated spectrum of exposure and experience; for example, some fellows were placed in one service, such as an emergency department, for the year without opportunity to rotate around other services. There was a balance to be made between flexibility and creating the variety of opportunities for experience that were expected.

I think the one thing, speaking to my other colleagues, is that there seems to be such variability in how the posts are in the fellowship ... other fellows get to rotate a bit more and I think I would have liked to have rotated into other posts as well. (Fellow 13)

If you make it too rigid then you deny them the opportunity of opportunistic learning but if you make it too fuzzy then everybody has a very individual experience. (HEE09)

There were mixed feelings about the length of placements, but it was generally felt longer placements enabled better embeddedness and in-depth learning, particularly in general practice:

I think being in one department for a whole year will perhaps give us more time to familiarise ourselves and actually produce some meaningful project work I think as well. (Fellow 14)

If the GP placements could be sort of a whole year rather than sixmonths because it sounds a bit like our fellow just kind of got going and then had to move on. (Mentor 08)

Overall participants felt positive about the fellowship programme, evidenced by their willingness to consider participating in future programmes or recommending it to colleagues. Fellows reported that the programme largely met their expectations, in line with its aims (Box 1), in particular helping them with leadership skills, system understanding and upskilling them in urgent care. The positive aspects that were described were very similar to those reported for the West Midlands pilot. ${ }^{17}$ As in the West Midlands pilot, all the fellows stated that they would recommend it to colleagues.

Yes, absolutely. [recommend it to others] I think it offers good experience in terms of just more variety to the GP work and good learning from the academic point of view and working with the CCGs. (F12)

Negative feedback centred on frustrations over lengthy contracting issues, relating to funding alterations, and the changes to placements discussed above.

\section{DISCUSSION}

This study has shown that a 1-year urgent/emergency care fellowship programme, developed in one region to address workforce challenges facing the NHS, can be successfully transferred to other contrasting areas. Through retaining core elements of the programme but being flexible in their implementation, fellows experienced a more variable but, in the main, equally valuable experience. In so doing, the programme appears to be successfully addressing the needs expressed by many newly qualified GPs who feel underprepared in managing patients with multi morbidities, ${ }^{9}$ and lacking expertise in management, leadership and quality improvement. ${ }^{19-22}$

The changes to the funding model resulted in concomitant changes to the arrangements of placements, leading to benefits and challenges. The new funding model should ensure the programme's sustainability, but a consequence was that greater priority is now placed on meeting host organisations' expectations and at times this negatively affected fellows' clinical placements. Increased flexibility in placement options enabled some fellows to tailor placements to their interests; however, others reported a lack of breadth in their clinical experience or control over where they were placed. Including access to placements in commissioning bodies and through being involved in quality improvement projects, the programme gave fellows experiences that go beyond the scope of GP vocational training. While time will tell the extent to which the fellowship programme develops future leaders, participants felt that the scheme was relevant to achieving this aim in the same way as had been evidenced by the West Midlands pilot. ${ }^{17}$ Most of the fellows at LaSE stated they would be looking for future positions encompassing clinical and leadership roles, with some from the first cohort already securing them.

The broadening of the programme to include multiprofessional fellows was welcomed with all groups seeing the benefits of cross-disciplinary learning. However, more guidance is required for host organisations on professional skillsets to maximise placement opportunity and satisfaction, including the need to understand it is not intended to be a competency-based programme.

Research on innovation and service change in the NHS has shown that there are many, wide ranging, factors that affect successful adoption, the complexity of which has been demonstrated. ${ }^{23}$ Common to many studies is the need for champions who take the innovation forward while the likelihood of success is improved with more senior champions. ${ }^{11} 16$ NHS organisations often rely on individuals taking on the role of champion as an additional task whereas innovation in other industries tends to be seen as a specialism it its own right. ${ }^{24}$ The need for adequately funded innovation projects alongside investment in capacity, skills and leadership has also been found crucial to successful adoption. ${ }^{25} 26$ The transfer of the fellowship from the West Midlands to LaSE benefited from key senior champions within HEE who drove the project forward. Where there were issues 
in securing placements, these could potentially be overcome with better understanding of the programme in secondary care and the co-opting of champions in host organisations. Another key element of successful innovation is reported to be a programme open to adaptation, refinement or modification. ${ }^{23}$ This research showed how the fellowship programme could be adapted to suit local needs in different areas without losing its core elements.

\section{Strengths and limitations}

The study had access to all the fellows that participated in the fellowship programme in 2016/2017 in LaSE, with 15 of the 17 fellows engaging with the evaluation. This gives strength to the representativeness of the views reported. Fellows were followed up on a number of occasions giving the opportunity to understand their experience at various stages of the fellowship. The study successfully collected views and expectations from the perspective of a wide range of individuals who worked with the fellows, giving depth to the findings.

One limitation of the study was the small number of non-GP fellows which precluded the separate analysis of this group. A further limitation was the time period over which the work was undertaken as we were unable to follow-up fellows over a long period of time after their programme had ended, therefore, cannot report how they were able to apply their experience in subsequent practice.

Although the study was limited to assessing the transferability of the programme from one region to another, the West Midlands and LaSE together cover $31.8 \%$ of the population of England ${ }^{27}$ and include 5 of the 13 local areas within two of the four regional Local Education Training Boards. Hence, it is likely that the findings have relevance to the rest of the country.

The financial model supporting the scheme was shown to be of fundamental importance to the success of the programme, influencing the way that clinical placements were identified and developed. However, it was beyond the scope of the study to undertake an economic evaluation of the programme. While this is an important consideration, the costs and benefits of the scheme need to be viewed over the medium to longer term in relation to how the fellowship is preparing clinicians to meet future workforce requirements, in addition to the return that fellows give to host organisations in the short term.

\section{Implications for practice}

There is a clear need for training for GPs and other primary care professionals in order to prepare for future NHS workforce needs. The evaluation of this fellowship programme demonstrates a model of training that is well received and accepted by fellows and those who work with or employ them. It appears to be suited to delivery within widely varying settings hence addressing the call for 250 fellowship placements to be made available across England. ${ }^{4}$ It could be modified to provide experience in a range of other priority clinical areas, such as mental health or frailty. This study highlights how it can be successfully adapted to fit with local funding and service requirements, while maintaining the balance with academic and leadership training and general practice experience. It has also shown the benefit of widening the programme to other primary care professional groups, although identified that careful consideration needs to be given to the choice of clinical placements. Cross-sector working will be increasingly important given growing numbers of individuals with multimorbidity and complex health needs being treated in primary care, and programmes like this will be valuable in building cross-sector and interprofessional understanding.

In conclusion, we have shown that a 1-year fellowship programme can be successfully transferred from one NHS region to another if flexibility and adaptation are enabled. The broader benefits that such fellowship schemes have to the participating health service organisations need further investigation.

Acknowledgements The authors thank all the health service staff who participated in the research along with staff at Health Education England

Contributors The study was designed by JD with CB and RR taking responsibility for the data collection. All were involved in the analysis, drafting and revision of the article.

Funding This study was carried out with funding from NHS Health Education England.

Competing interests None declared.

Patient consent Not required.

Ethics approval University of Warwick's Biomedical and Scientific Research Ethics Sub-Committee: REG0-2016-1828 AM02.

Provenance and peer review Not commissioned; externally peer reviewed. Data sharing statement There are no unpublished data available for this study.

Open access This is an open access article distributed in accordance with the Creative Commons Attribution Non Commercial (CC BY-NC 4.0) license, which permits others to distribute, remix, adapt, build upon this work non-commercially, and license their derivative works on different terms, provided the original work is properly cited, appropriate credit is given, any changes made indicated, and the use is non-commercial. See: http://creativecommons.org/licenses/by-nc/4.0/.

\section{REFERENCES}

1. NHS England. Five year forward view. Leeds: NHS England, 2014. https://www.england.nhs.uk/wp-content/uploads/2014/10/5yfv-web. pdf. (accessed 26 Oct 2017).

2. NHS England. New care models: Vanguards-developing a blueprint for the future of NHS and care services. London: NHS England, 2016. https://www.england.nhs.uk/wp- content/uploads/2015/11/new_ care_models.pdf. (accessed 26 Oct 2017).

3. NHS England. Building the Workforce-the New Deal for General Practice. Secondary Building the workforce: the new deal for general practice: NHS England, 2015. https://www.england.nhs.uk/ commissioning/wp- content/uploads/sites/12/2015/01/building-theworkforce-new-deal-gp.pdf. (accessed 26 Oct 2017).

4. NHS England. General practice forward view: NHS England, 2016. https://www.england.nhs.uk/wp-content/uploads/2016/04/gpfv.pdf. (accessed 26 Oct 2017).

5. Gibson J, Checkland K, Coleman A, et al. Eighth national GP worklife survey: University of Manchester, 2015.

6. Dale J, Potter R, Owen K, et al. Retaining the general practitioner workforce in England: what matters to GPs? A cross-sectional study. BMC Fam Pract 2015;16:140.

7. Primary Care Workforce Commission. The future of primary care: creating teams for tomorrow. London: Health Education England, 2015. https://www.hee.nhs.uk/sites/default/files/documents/The\% 
20Future\%20of\%20Primary\%2 0Care\%20report.pdf. (accessed 23 Nov 2017)

8. Greenaway D. Securing the future of excellent patient care. London: Shape of Training, 2013. https://www.shapeoftraining.co.uk/ static/documents/content/Shape_of_training_FINAL_Re port.pdf 53977887.pdf. (accessed 26 Oct 2017).

9. Sabey A, Hardy H. Views of newly-qualified GPs about their training and preparedness: lessons for extended generalist training. $\mathrm{Br} J \mathrm{Gen}$ Pract 2015;65:e270-e277.

10. Gilburt $\mathrm{H}$. Supporting integration through new roles and working across boundaries: King's Fund. 2016 https://www.kingsfund.org.uk/ sites/default/files/field/field_publication_file/Supporting_integration_ web.pdf (accessed 26 Oct 2017)

11. Collins B. Adopton and spread of innovation in the NHS. London: The King's Fund, 2018. https://www.kingsfund.org.uk/sites/default/ files/2018-01/Adoption_and_spread_of_innovation_NHS_0.pdf. (accessed 24 Jan 2018).

12. Lau R, Stevenson F, Ong BN, et al. Achieving change in primary care-causes of the evidence to practice gap: systematic reviews of reviews. Implementation Science 2015;11:40.

13. Pace LE, Dolan BM, Tishler LW, et al. Incorporating long-acting reversible contraception into primary care: a training and practice innovation. Womens Health Issues 2016;26:131-4.

14. Ono SS, Crabtree BF, Hemler JR, et al. Taking innovation to scale in primary care practices: the functions of health care extension. Health Aff 2018;37:222-30.

15. Greenhalgh T, Stramer K, Bratan T, et al. Introduction of shared electronic records: multi-site case study using diffusion of innovation theory. BMJ 2008;337:a1786.

16. Lord L, Dowswell G, Hewison A. 'The team for both sides?' A qualitative study of change in heart failure services at three acute NHS Trusts. Health Soc Care Community 2015;23:121-30.

17. Dale J, Russell R, Harkness F, et al. Extended training to prepare GPs for future workforce needs: a qualitative investigation of a 1-year fellowship in urgent care. Br J Gen Pract 2017;67:e659-e667.
18. Gale NK, Heath G, Cameron E, et al. Using the framework method for the analysis of qualitative data in multi-disciplinary health research. BMC Med Res Methodol 2013;13:117.

19. Riley B, Howe A. Pushing for victory: where next for 4-year GP training? Br J Gen Pract 2015;65:52-3.

20. Taylor C, Turnbull C, Sparrow N. Establishing the continuing professional development needs of general practitioners in their first five years after training. Educ Prim Care 2010;21:316-9.

21. Dale J, Russell R, Scott E, et al. Factors influencing career intentions on completion of general practice vocational training in England: a cross-sectional study. BMJ Open 2017;7:e017143.

22. Foundation H. Quality improvement training for healthcare professionals. London: The Health Foundation, 2012. http://www. health.org.uk/sites/health/files/QualitylmprovementTrainingForHea IthcareProfessionals.pdf. (accessed 24 Jan 2018).

23. Greenhalgh T, Robert G, Macfarlane F, et al. Diffusion of innovations in service organizations: systematic review and recommendations. Milbank Q 2004;82:581-629.

24. Heitmueller A, Bull A, Oh S. Looking in the wrong places: why traditional solutions to the diffusion of innovation will not work: Table 1. BMJ Innov 2016;2:41-7.

25. Kelly CJ, Young AJ. Promoting innovation in healthcare. Future Hospital Journal 2017;4:121-5.

26. Parris S, Cochrane G, Marjanovic S, et al. Galvanising the nhs to adopt innovation: the feasibility and practicality of recommendations from the interim report of the accelerated access review. Rand Health Q 2016;6

27. ONS. Annual small area population estimates. Fareham: Office for National Statistics 2017 https://www.ons.gov.uk/peoplepopula tionandcommunity/populationandmigration/populationestimates/ datasets/clinicalcommissioninggroupmidyearpopulationestimates (accessed 22 Feb 2018). 